Miami Nature Biotechnology Short Reports

TheScientificWorld (2001) 1 (S3), 120SR

ISSN 1532-2246; DOI 10.1100/tsw.2001.218

\title{
MACROPHAGE APOPTOSIS INDUCED BY AN AVIAN STRAIN OF Escherichia coli
}

\author{
Fabiana Horn*, Michele Bastiani, and Diógenes S. Santos \\ Departamento de Biofísica and Departamento de Biotecnologia, Universidade Federal do Rio \\ Grande do Sul, PO Box 15005, Porto Alegre 91501-970, Brasil \\ * fhorn@dna.cbiot.ufrgs.br
}

INTRODUCTION. The avian Escherichia coli strain UEL17 has been reported to cause apoptosis in mouse peritoneal phagocytes (1), as judged by TUNEL assay, electrophoresis of total DNA and HE staining. Here we show that UEL17 causes cell death also in the macrophage cell line J774, as observed by LDH liberation, and tested the involvement of 5 caspases in this process.

METHOD. Macrophages J774, plated at $7,5 \times 10^{4} \mathrm{cell} / \mathrm{cm}^{2}$, were infected with UEL17 or M90T (positive control, ref. 2) in RPMI 1640 plus glutamine. After $1 \mathrm{~h}$, cells were washed and incubated further in the presence of gentamicyn $50 \mu \mathrm{g} / \mathrm{ml}$ to complete $4 \mathrm{~h}$ from infection. LDH was measured using the Cytotox96 kit (Promega), following the manufacturer's instructions. To measure caspase activity, cells were lysed and the extracts incubated with 5 fluorogenic substrates; the reaction was monitored at $370 / 460 \mathrm{~nm}$.

RESULTS. J774 cells infected with UEL17 at a multiplicity of infection (MOI) of 20, 50 and 150 bacteria per cell presented a corresponding number of internalized bacteria (below, a, b and c); when M90T was used (MOI of 150), J774 cells showed an average of 5 bacteria per cell. The LDH liberation (Fig. 1; control $\mathbf{\square}$; M90T O; UEL17 @) from cells infected with either bacteria (both at a MOI of 150) indicated cell death, in agreement with previous results $(1,2)$. For caspase activation, we tested the hydrolysis, by the cell extracts, of the following substrates: Ac-YVAD-MCA (for caspase1/4), Ac-DEVD-MCA (caspase 3/7), Ac-VEID-MCA (caspase-6), Ac-IETD-MCA (caspase 6/8), Ac-LEHD-MCA (caspase-9). We only detected hydrolysis of the substrate

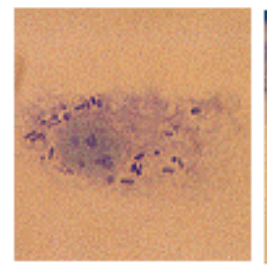

a

Fig. 1

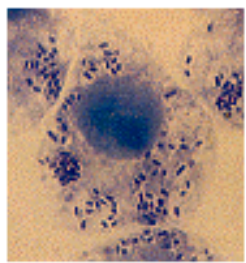

b

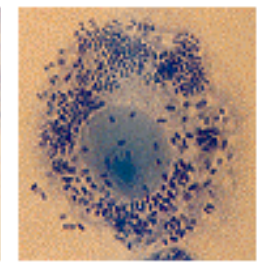

C

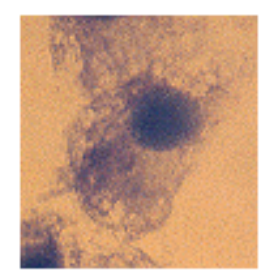

control

Fig. 2 

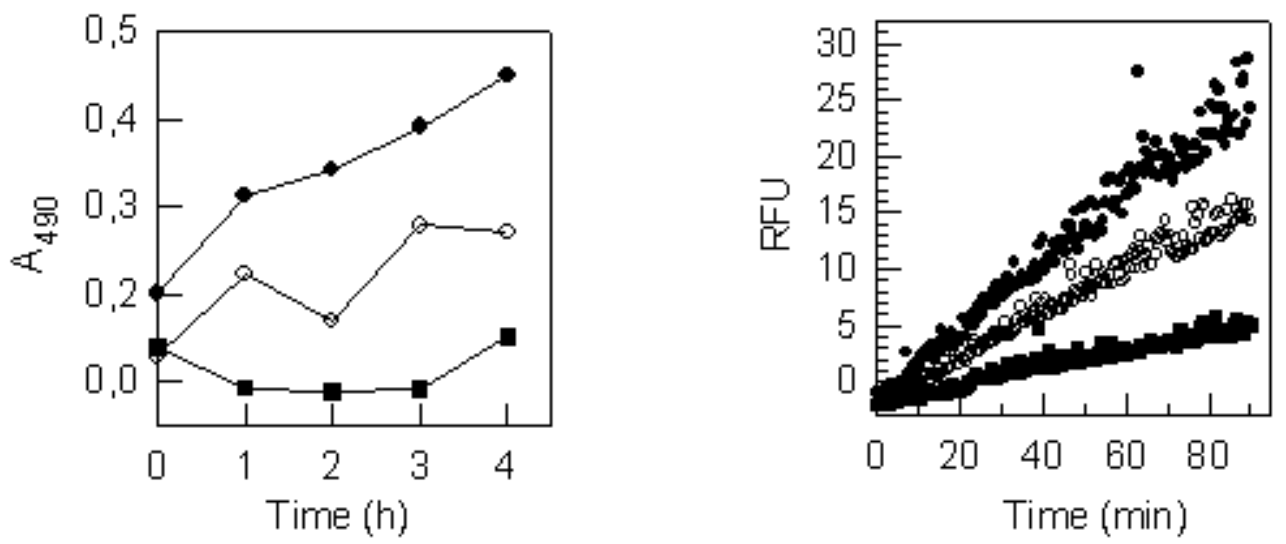

Ac-DEVD-MCA (Fig. 2; control $\mathbf{\square}$; M90T $\bigcirc$; UEL17 @), indicating that caspase-3/7 is involved in apoptosis induced by UEL17 infection.

DISCUSSION. Macrophage apoptosis caused by UEL17 infection involves caspase-3 activation. Since caspase-8 does not appear to be activated, as expected if apoptosis was triggered by Fas activation, it is possible that UEL17 interferes directly with a caspase downstream of caspase-8.

ACKNOWLEDGEMENTS. This work was supported by Fundação de Amparo à Pesquisa do Estado do Rio Grande do Sul (FAPERGS).

\section{REFERENCES.}

1. Rodrigues, V.S., Vidotto, M.C., Felipe, I., Santos, D.S., and Gaziri, L.C.J. (1999) FEMS Microbiol Lett. 179, 73

2. Zychlinsky, A., Prevost, M.C., and Sansonetti, P.J. (1992) Nature 358, 167 


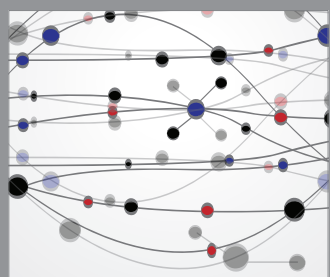

The Scientific World Journal
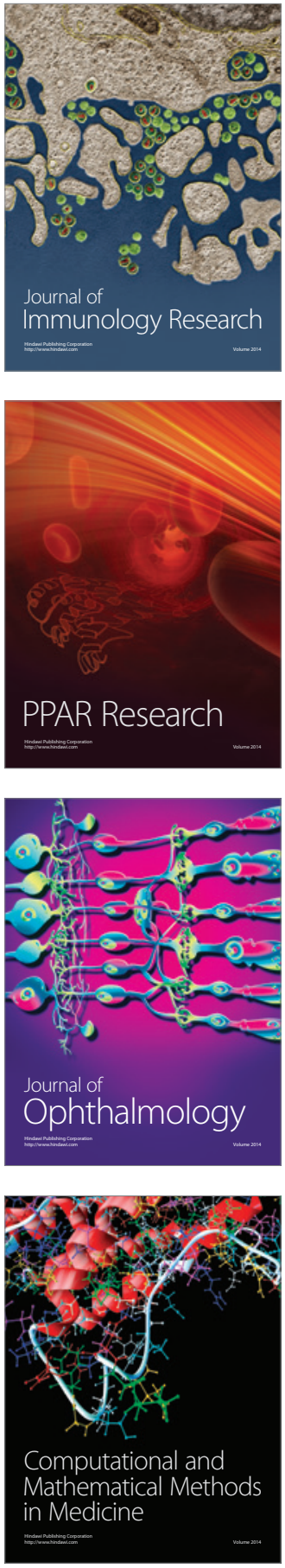

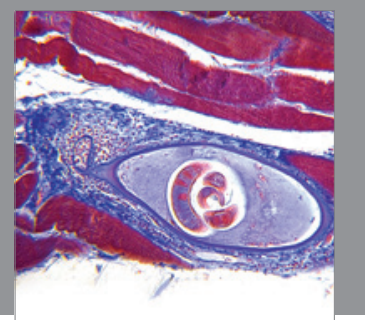

Gastroenterology

Research and Practice
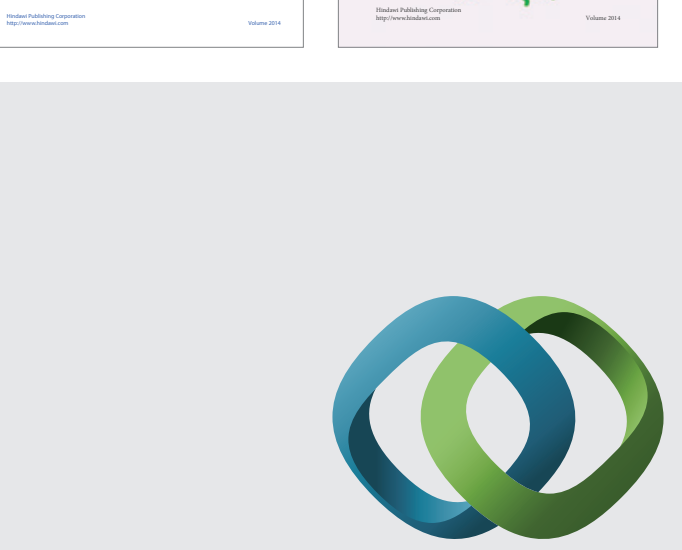

\section{Hindawi}

Submit your manuscripts at

http://www.hindawi.com
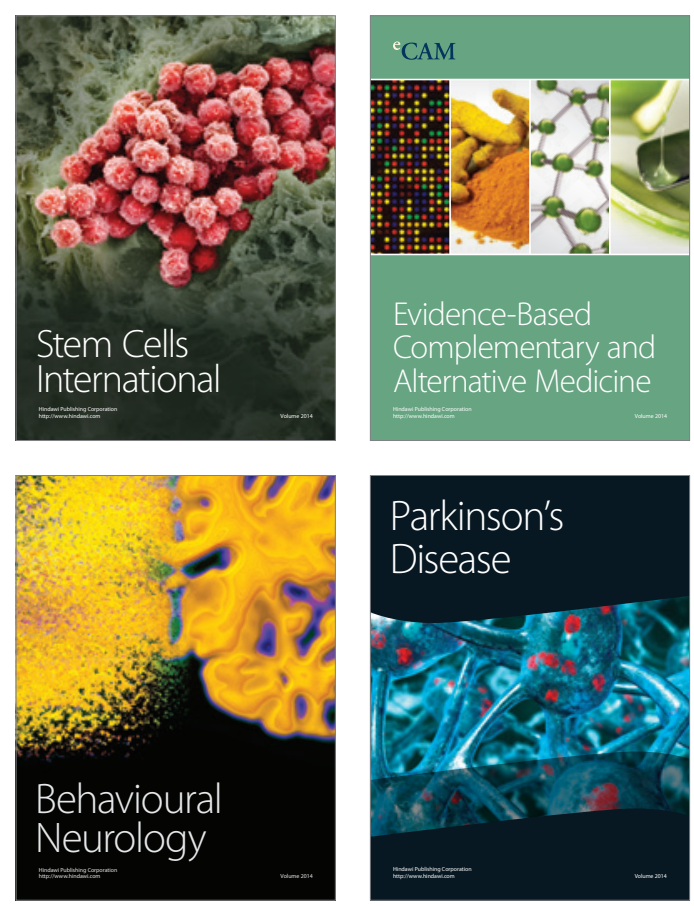

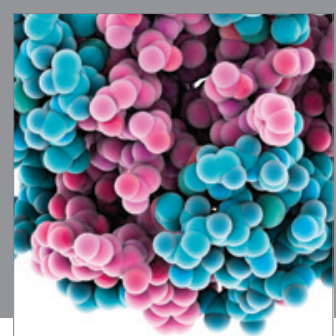

Journal of
Diabetes Research

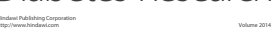

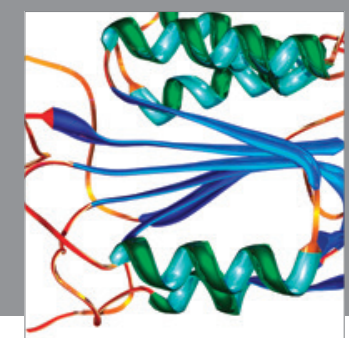

Disease Markers
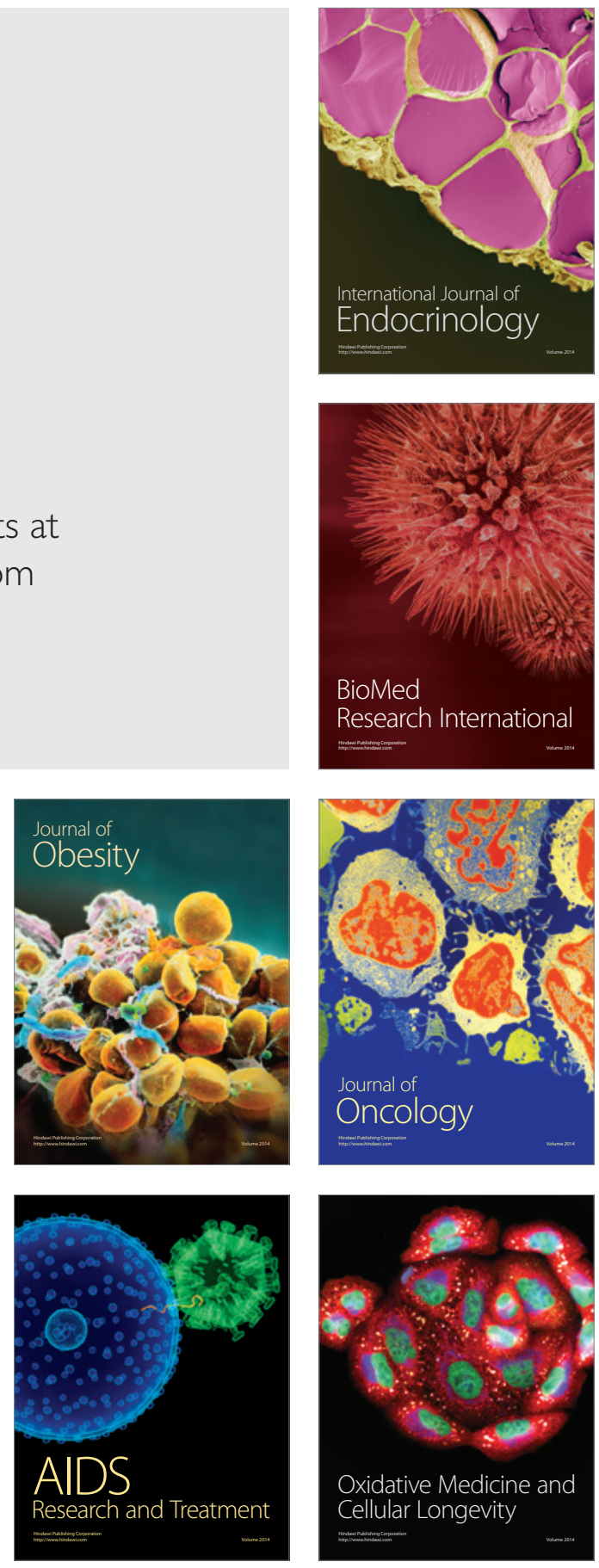